\title{
20 años fenomenales
}

institucionales.us.es/ambitos/

\section{José Manuel de Pablos}

Universidad de La Laguna

jpablos@ull.es

Con mi felicitación a los primeros 20 años de Ámbitos

"El depredador te ve, pero tú no ves al depredador" Henning Mankell

(Arenas movedizas, 2015, 123)

Dicen o dícese que 20 años no son nada. Es de suponer que eso vale para 20 años absurdos, aburridos o tiempo que no ha dejado huella.

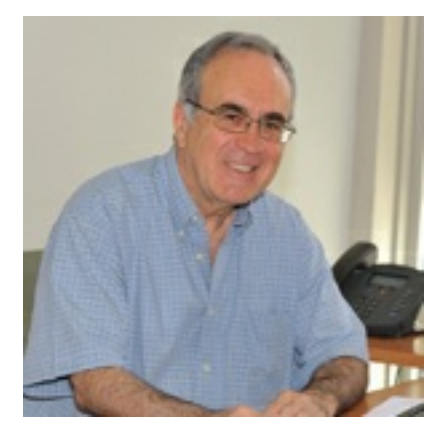

Los últimos 20 años no son de ese tipo. Han sido 20 años grandes e igual de miserables, porque hemos visto cómo se establecía con plenitud manifiesta el tiempo oficial de las mentiras y el miedo civil insuflado desde el 2018 poder, el gobierno del deshonor declarado y la era del cinismo evidente. El depredador no ha descansado.

Mas, también han sido años de buenos recuerdos, de iniciativas que han triunfado... del crecimiento de la esperanza. Un tiempo durante el cual nos hemos fortalecido, en los cuales hemos crecido algo, hemos seguido aprendiendo y admirando a maestras y maestros, aunque con algo de timidez, y esto es un lamento. Entre otras realidades, hemos visto cómo se empieza a superar el techo de cristal para las compañeras en la academia, con excesiva lentitud.

Bien es verdad que el espanto se ha establecido de igual manera en una sociedad que no acaba de arrancarse viejos modelos de no-ciudadanía, que parece que tiene temor a ser ciudadana y no súbdita, de no dar garrote a viejos tiempos y dejarse deslumbrar por el nacimiento de una democracia sin más, sin apellidos ni padrinazgos falsos. El demo español es muy particular. ¡Pobre! Y permanece deslumbrado por el cinismo del poder y de por quienes lo ejercen. Ello, con la triste complicidad de tantos medios que sirven al poderoso, que al fin y al cabo su amo es.

Una de las 'perlas' más embarradas ha sido, a mi entender, claro, las contenidas en las palabras de un tertuliano, que llegó a criticar el proceso independentista catalán, señalando sin pudor ni vergüenza que de lo que se trataba era de una "apología del referéndum". Nunca había visto ni escuchado con escándalo y vergüenza ajenas ese maridaje entre "apología” y consulta popular. Nunca. Irrepetible. Aunque mentes enfermas haylas.

En los países democráticos donde la consulta a la población está a la orden del día, ese sentimiento en un medio habrá sido otro motivo más para escandalizar al mundo civilizado, 
en un proceso que siguió con el encarcelamiento de varios políticos, por el mero hecho de serlo, que no por otra sinrazón... (Claro, que si nos ponemos a recordar el cruel maltrato proporcionado por Francia a los refugiados españoles tras el golpe del 36... esa desvergüenza solo lo será exclusivamente entre los librepensadores del mundo civilizado, no de sus medios ni de sus gobernantes depredadores).

Veinte años, fenomenales porque los hemos vivido. Pero, ¿es suficiente para otorgarles ese nivel, esa cualidad? Ha sido un tiempo donde hemos visto en primera persona el desarrollo imparable y global de la técnica ideada por Tim Berners-Lee en Ginebra y todo lo que la ha estado acompañando durante esos 20 años de arranque y pleno establecimiento global. Ha sido un periodo donde hemos sido sorprendidos -a veces con temores fundados- por tecnologías aplicadas que han socializado las comunicaciones interpersonales y que dejan patente que la red conectada es el futuro adelantado a nuestras existencias.

El desarrollo acelerado y extensivo de la telefonía móvil ha validado aquella teoría que aseguraba que veríamos un desarrollo inusual de la imagen fotografiada y presentada en los medios, y así ha ocurrido y de esa manera está sucediendo en los digitales -que siguen siendo los únicos medios de comunicación social que tienen el futuro en sus cuadernas- y las comunicaciones de persona a persona, con la correspondiente viralización de contenidos, como vemos a diario, cuando una persona se hace emisora y cualquier otra difunde ese mensaje recibido, como nunca había sucedido. Como nunca se había visto. Y es lógico.

Cuando surge una nueva técnica o una nueva aplicación de la técnica diferente, cada vez se implanta antes en la sociedad, y tarda menos en instalarse. Ya toda persona está equipada para ello. Material y mentalmente. El doble cambio ya se ha transformado en uno único y bien confundido. Se han fusionado entre sí la innovación de técnica con la evolución de la mentalidad que va a manejar esa nueva pericia. Hace 20 años esto no era así y la llegada del cambio tecnológico tardaba en hacerse un hueco en la sociedad civil.

Cuando llega la nueva técnica y se hace sólida en la sociedad, como nunca la humanidad pudiente -que no es toda, es solo la humanidad rica, la que tiene recursos solo soñados en países con riquezas naturales pero explotados por las multinacionales de los lugares más favorecidos del planeta- goza de sus producciones, se beneficia de la facilidad para lograr viejas producciones con menos gasto en todo. "Como nunca" exclamarían los alemanes de Maguncia cuando la primera imprenta de tipos movibles empezó a producir libros "como nunca" había sucedido antes del revolucionario Gutenberg. Éste, otro transformador, como hace poco lo ha sido el ya citado Berners-Lee.

El "como nunca" va a ser el tópico que acompañe a nuevas técnicas y novedosas aplicaciones que están por llegar y asentarse entre nosotros. Hay un punto muy a su favor y es que la sociedad actual -dentro de su patético pasotismo y manifiesta vulgaridad (la misma del "esto es lo que hay", "más vale malo conocido que bueno por conocer", "del rey abajo, ninguno", la misma del "Vivan las caenas", que aplaude cacerías de elefantes y soporta una monarquía bananera)- están más dispuestas a recibir las insólitas 
modalidades de comunicación y a hacerlas suyas y, como tales, a favorecer su plena instalación en una humanidad que hoy derrocha tecnologías y que ha de madurar algún día...

En todo caso, los últimos 20 años han sido muy fructíferos, nos han permitido conocer mejor y disfrutar más en libertad de algunos de los episodios de nuestra vida cotidiana. Lo que ha sucedido es que esa libertad se ha derrochado en sensiblerías, como los programa basura de la televisión de cada tarde.

Esa sociedad, si fuera capaz - ¡difícil, sin duda!- de apartar las garras de la presente edad del cinismo y denunciarla allá donde la vea aparecer, de sacudirse una impudicia que nos embarra tantas veces, de alejar de nuestro pensamiento los repetidos rasgos de corrupción política vieja y "popular" que nos inunda y de dejar de mirar hacia las flores del jardín municipal y de aplicar crítica al contenido de los medios que consume... hasta sería posible que fuéramos más felices. Por eso los invito a reflexionar con tantos capítulos que amargan muchas vidas, para acercarnos -aunque solo fuera aproximarse- a unos años que de verdad sean fenomenales para muchos más, erigidos en fruidores de la vida de cada día.

\section{BREVE SEMBLANZA DEL AUTOR:}

José Manuel de Pablos es doctor en Periodismo por la Universidad Complutense. Formado en la prensa de Madrid, ha sido director en dos ocasiones en prensa de Tenerife, donde reside. Catedrático de Periodismo de la Universidad de La Laguna desde los años 90. Fundador de Revista Latina de Comunicación Social (1998), journal situado en el primer cuartil de Scopus, según la última actualización, con datos de 2016. Entre sus libros destacan El periodismo herido. Estudios que delatan divorcio entre prensa y sociedad. El País, como referente, sobre el periódico El País (Madrid, Foca Investigación, 2001,) y La red es nuestra. El periódico telemático, la revista en línea, la radio digital y el libro web cambiarán las formas de comunicación Social (Barcelona, Paidós, 2001).

Ámbitos. Revista Internacional de Comunicación, n.40, edición de primavera, 2018. 